\title{
Study on Quality of Hot Mix Plant Recycling Mixture under Influence of RAP Performance
}

\author{
Ping $\mathrm{Wu}^{1,2}$ \\ ${ }^{1}$ Changan University, Xi,an, Shaanxi, China \\ ${ }^{2}$ Road and Bridge Limited Liability Company of Inner Mongolia, Hohhot, Inner Mongolia, China
}

\begin{abstract}
To explore the variation of hot mix plant recycling mixture design parameters and quality under the influence of RAP performance, represent index and factor level of RAP performance were determined, the variation of mix proportion design parameters was comprehensively analysised under different indexes and levels based on orthogonal test, and then the pavement performance was studyed. The result showed that: the fineness modulus of RAP had the most significant effect on design parameters, and then followed by asphalt content and aging degree. The aging degree of RAP had the most significant effect on mechanical properties of regeneration mixture. The high temperature properties were improved by a certain degree with a high aging degree, but then the water stability decreased significantly. And the high temperature properties of regeneration mixture decreased as the increasing of fineness modulus of RAP.
\end{abstract}

Keywords-road engineering; RAP performance; intuitive analysis; design parameters; pavement performance

\section{INTRODUCTION}

The existed statistical results of survey datas showed that, 90 percents of total highway in our country were asphalt pavements, lots of waste would be produced during the process of maintaining and repairing, this phenomenon would bring about many adverse effects such as taking up valuable land, polluting the environment and wasting of resources if withnot using effectly [1].The hot mix plant recycling technology had been widely studied and applied because of many advantages such as protecting non-renewable energy, reducing the burden of environmental, saving energy and so on [2]. As an important part of hot mix plant regeneration mixture, the performance and index situation of RAP had an directly influence on the process of mix proportion design and adding proportion, and then determined the quality and performance of regeneration mixture [3-4]. The performance divergence of RAP was obvious due to different reasons, the variability was mainly revealed through volatility of asphalt content, aging degree and fineness modulus of RAP [5]. If the influence degree that RAP performance had on the regeneration mixture could not be cleared, the quality of regeneration mixture could not be guaranteed [6].

To solve these problems, in this paper the influence mechanism that RAP performance had on the quality of regeneration mixture was cleared, and then the represent indexes and factors level of RAP performance were determined, the variation of mix proportion design parameters under influence of influencing factors and levels was analysised based on orthogonal test, pavement performance was studied under different factor levels, the results provided reference for mix proportion designation, the quality of regeneration mixture was improved.

\section{QuAlity Influencing Factors OF Hot MiX Plant RECYCLING MIXTURE}

RAP materiasl were the main part of hot mix plant recycling mixture, including of old materials, adding proportion of new asphalt and aggregate, and the adding of recycling agent were all decided by RAP performance. The asphalt content and performance varied in different degree road and pavement structure, the content of new asphalt and variety of regenerant were decided by aging degree and content of RAP. The gradation of RAP had a direct impact on design of mix proportion, aggregate would be knapped when being excavated and milling-planed, bring about the increasing of fine aggregate content, the segregation phenomenon would be easily occurred and always could not met the repuire of gradation. Seen from the above analysis, asphalt content, aging degree and gradation were the representive index of RAP performance, so in this paper they would be deeply studied.

\section{DESIGN OF EXPERIMENTAL SCHEME}

In this paper orthogonal test was determined to act as the sdudying method, the specific test method was as follows:(1)The aging degree of asphalt in RAP was measured by $25^{\circ} \mathrm{C}$ penetration. The existing research showed that: $25^{\circ} \mathrm{C}$ penetration of different RAP materials varied in the range of $10 \sim 40(0.1 \mathrm{~mm})$, so three different levels of aging degree were determined during study, they were $10,20,40(0.1 \mathrm{~mm})$. (2)The existing research showed that: asphalt content of RAP varied in the range of $3.5 \% \sim 4.5 \%$, so three different levels were determined, they were $3.5 \%, 4 \%, 4.5 \%$. (3)Aggregate Gradation was composed of passing rate of different sieves, key sieve had a greater impaction on designing of mix proportion and pavement performance, if selecting one of them to characterize aggregate gradation was obviously one-sided. Therefore, this article borrowed the concept of fineness modulus coming from US ASTMC136 to characterize aggregate gradation, it was calculated as shown in Formula1, three different levels of fineness modulus were determined,they were 5.0,4.6,4.2.

$$
M_{\chi}=\frac{\left(A_{0.15}+A_{0.3}+A_{0.6}+A_{1.18}+A_{2.36}+A_{4.75}+A_{9.5}+A_{13.2}+A_{16}\right)}{100}
$$

Mx_-fineness modulus; Ax_—cumulative knockings percentage of sieve pore(\%). 
The orthogonal test influencing factors, level and plan that were determined finally in this article were showed in TABLE1.

TABLE I.

\begin{tabular}{|c|c|c|c|}
\hline \multirow{2}{*}{$\begin{array}{c}\text { Serial } \\
\text { number }\end{array}$} & \multicolumn{3}{|c|}{ Influencing Factor } \\
\hline & $\begin{array}{c}\text { A: penetration } \\
(0.1 \mathrm{~mm})\end{array}$ & $\begin{array}{r}\text { B: asphalt } \\
\text { content }(\%)\end{array}$ & $\begin{array}{l}\text { C: fineness } \\
\text { modulus }\end{array}$ \\
\hline 1 & 10 & 3.5 & 5.0 \\
\hline 2 & 10 & 4.0 & 4.6 \\
\hline 3 & 10 & 4.5 & 4.2 \\
\hline 4 & 20 & 3.5 & 4.6 \\
\hline 5 & 20 & 4.0 & 4.2 \\
\hline 6 & 20 & 4.5 & 5.0 \\
\hline 7 & 40 & 3.5 & 4.2 \\
\hline 8 & 40 & 4.0 & 5.0 \\
\hline 9 & 40 & 4.5 & 4.6 \\
\hline
\end{tabular}

According to the program of orthogonal test, three kinds of raw RAP materials were necessaried to configure nine kinds of test RAP materials that met the standard in Table1, the principle that must be followed were keeping the property of asphalt, and just added some new mineral aggregate so that asphalt content and fineness modulus met the standard.
Because of the restriction by RAP material source, it was difficult to get composite material that completely met the standard in Table1, the asphalt content, penetration and fineness modulus although had a certain bias, but overall was able to meet the test required.

\section{Study ON Change LAW OF Design PARAMETERS UNDER INFLUENCE OF RAP PERFORMANCE}

Selecting gradation and determining the optimum asphalt content always depended on experience in the process of component design, and then finally selected the volume composition of mixture after compaction as a final judgment. The variability of raw RAP materials inevitably lead to the fluctuation of design parameters, so it was necessary to study on the change law of design parameters under the influence of different RAP meterial. The mixing amount of RAP was 30\% during test, formed 9 kinds of marshall specimens, tested the physical and mechanical properties,the results were showed in TABLE2.

TABLE II.

THE VOLUME OF RECYCLED MIXTURE PROPORTIONING DESIGN PARAMETER VALUES

\begin{tabular}{|c|c|c|c|c|c|c|c|}
\hline $\begin{array}{c}\text { Serial } \\
\text { number }\end{array}$ & $\begin{array}{c}\text { Relative Bulk } \\
\text { density }\end{array}$ & $\begin{array}{c}\text { Theoretical maximum relative } \\
\text { density }\end{array}$ & $\begin{array}{c}\text { VV } \\
(\mathbf{\%})\end{array}$ & $\begin{array}{c}\text { VMA } \\
(\mathbf{\%})\end{array}$ & $\begin{array}{c}\text { VFA } \\
(\mathbf{\%})\end{array}$ & $\begin{array}{c}\text { MS } \\
(\mathbf{K N})\end{array}$ & $\begin{array}{c}\text { FL } \\
(\mathbf{m m})\end{array}$ \\
\hline 1 & 2.42 & 2.542 & 3.94 & 15.43 & 74.34 & 11.25 & 2.23 \\
\hline 2 & 2.43 & 2.537 & 3.37 & 14.31 & 76.68 & 12.93 & 2.43 \\
\hline 3 & 2.46 & 2.524 & 2.04 & 13.13 & 84.57 & 12.94 & 3.07 \\
\hline 4 & 2.42 & 2.548 & 4.12 & 15.11 & 71.94 & 10.96 & 2.36 \\
\hline 5 & 2.47 & 2.581 & 3.40 & 14.60 & 76.32 & 11.85 & 2.41 \\
\hline 6 & 2.45 & 2.569 & 3.73 & 14.81 & 74.22 & 10.26 & 2.41 \\
\hline 7 & 2.46 & 2.577 & 3.63 & 14.67 & 74.59 & 9.32 & 2.43 \\
\hline 8 & 2.42 & 2.562 & 4.64 & 15.62 & 69.34 & 8.60 & 2.57 \\
\hline 9 & 2.47 & 2.573 & 3.15 & 14.51 & 78.11 & 10.63 & 2.71 \\
\hline
\end{tabular}

To clearly analyze the influence law of design parameters under different influencing factors and levels, the intuitive

analysis method was selected to analyze the test results, intuitive analysis results were showed in TABLE3.

TABLE III. VISUAL ANALYSIS OF VOLUME PARAMETERS

\begin{tabular}{|c|c|c|c|c|c|c|c|c|c|c|c|}
\hline \multicolumn{4}{|c|}{ VVintuitive analysis（\%) } & \multicolumn{4}{|c|}{ VMAintuitive analysis (\%) } & \multicolumn{4}{|c|}{ FLintuitive analysis $(\mathrm{mm})$} \\
\hline $\mathrm{T}_{1}$ & 9.35 & 11.69 & 12.31 & $\mathrm{~T}_{1}$ & 42.87 & 45.21 & 45.86 & $\mathrm{~T}_{1}$ & 7.73 & 7.02 & 7.21 \\
\hline $\mathrm{T}_{2}$ & 11.25 & 11.41 & 10.64 & $\mathrm{~T}_{2}$ & 44.52 & 44.53 & 43.93 & $\mathrm{~T}_{2}$ & 7.18 & 7.41 & 7.5 \\
\hline $\mathrm{T}_{3}$ & 11.42 & 8.92 & 9.07 & $\mathrm{~T}_{3}$ & 44.8 & 42.45 & 42.40 & $\mathrm{~T}_{3}$ & 7.71 & 8.19 & 7.91 \\
\hline $\mathrm{t}_{1}$ & 3.12 & 3.90 & 4.10 & $\mathrm{t}_{1}$ & 14.29 & 15.07 & 14.64 & $\mathrm{t}_{1}$ & 2.58 & 2.34 & 2.40 \\
\hline $\mathrm{t}_{2}$ & 3.75 & 3.80 & 3.55 & $\mathrm{t}_{2}$ & 14.84 & 14.84 & 15.29 & $\mathrm{t}_{2}$ & 2.39 & 2.47 & 2.50 \\
\hline$t_{3}$ & 3.81 & 2.97 & 3.02 & $\mathrm{t}_{3}$ & 14.93 & 14.15 & 14.13 & $\mathrm{t}_{3}$ & 2.57 & 2.73 & 2.64 \\
\hline range & 0.69 & 0.93 & 1.08 & range & 0.64 & 0.92 & 1.16 & range & 0.19 & 0.39 & 0.24 \\
\hline $\begin{array}{c}\text { primary and } \\
\text { secondary } \\
\text { factor }\end{array}$ & \multicolumn{3}{|c|}{$\mathrm{C} \geq \mathrm{B} \geq \mathrm{A}$} & $\begin{array}{l}\text { primary and } \\
\text { secondary } \\
\text { factor }\end{array}$ & \multicolumn{3}{|c|}{$\mathrm{C} \geq \mathrm{B} \geq \mathrm{A}$} & $\begin{array}{l}\text { primary and } \\
\text { secondary } \\
\text { factor }\end{array}$ & \multicolumn{3}{|c|}{$\mathrm{B} \geq \mathrm{C} \geq \mathrm{A}$} \\
\hline \multicolumn{4}{|c|}{ VFAintuitive analysis $(\%)$} & \multicolumn{4}{|c|}{ MS intuitive analysis ( $\mathrm{KN})$} & & & & \\
\hline $\mathrm{T}_{1}$ & 235.59 & 220.87 & 217.90 & $\mathrm{~T}_{1}$ & 37.12 & 31.53 & 30.11 & & & & \\
\hline $\mathrm{T}_{2}$ & 222.48 & 222.34 & 226.73 & $\mathrm{~T}_{2}$ & 33.07 & 33.38 & 34.52 & & & & \\
\hline $\mathrm{T}_{3}$ & 222.04 & 236.90 & 235.48 & $\mathrm{~T}_{3}$ & 28.55 & 33.83 & 34.11 & & & & \\
\hline $\mathrm{t}_{1}$ & 70.83 & 73.62 & 72.63 & $\mathrm{t}_{1}$ & 12.37 & 10.51 & 10.04 & & & & \\
\hline $\mathrm{t}_{2}$ & 74.16 & 74.13 & 75.58 & $\mathrm{t}_{2}$ & 11.02 & 11.13 & 11.50 & & & & \\
\hline$t_{3}$ & 74.01 & 78.97 & 78.49 & $t_{3}$ & 9.52 & 11.28 & 11.37 & & & & \\
\hline range & 3.33 & 5.35 & 5.86 & range & 2.85 & 0.77 & 1.46 & & & & \\
\hline $\begin{array}{c}\text { primary and } \\
\text { secondary } \\
\text { factor }\end{array}$ & \multicolumn{3}{|c|}{$\mathrm{C} \geq \mathrm{B} \geq \mathrm{A}$} & $\begin{array}{l}\text { primary and } \\
\text { secondary } \\
\text { factor }\end{array}$ & \multicolumn{3}{|c|}{$\mathrm{A} \geq \mathrm{C} \geq \mathrm{B}$} & & & & \\
\hline
\end{tabular}


It could be seen from intuitive analysis results:

(1)The order of influence degree that RAP performance had on VV, VMA, and VFAshowed bellow: fineness modulus $\geq$ asphalt content $\geq$ penetration; As for the stability, the order showed bellow: penetration $\geq$ fineness modulus $\geq$ asphalt content; As for the FL, the order showed bellow: asphalt content $\geq$ fineness modulus $\geq$ penetration.

(2)It could be seen from the sort of influencing degree that RAP performance had on the mix proportion design volume
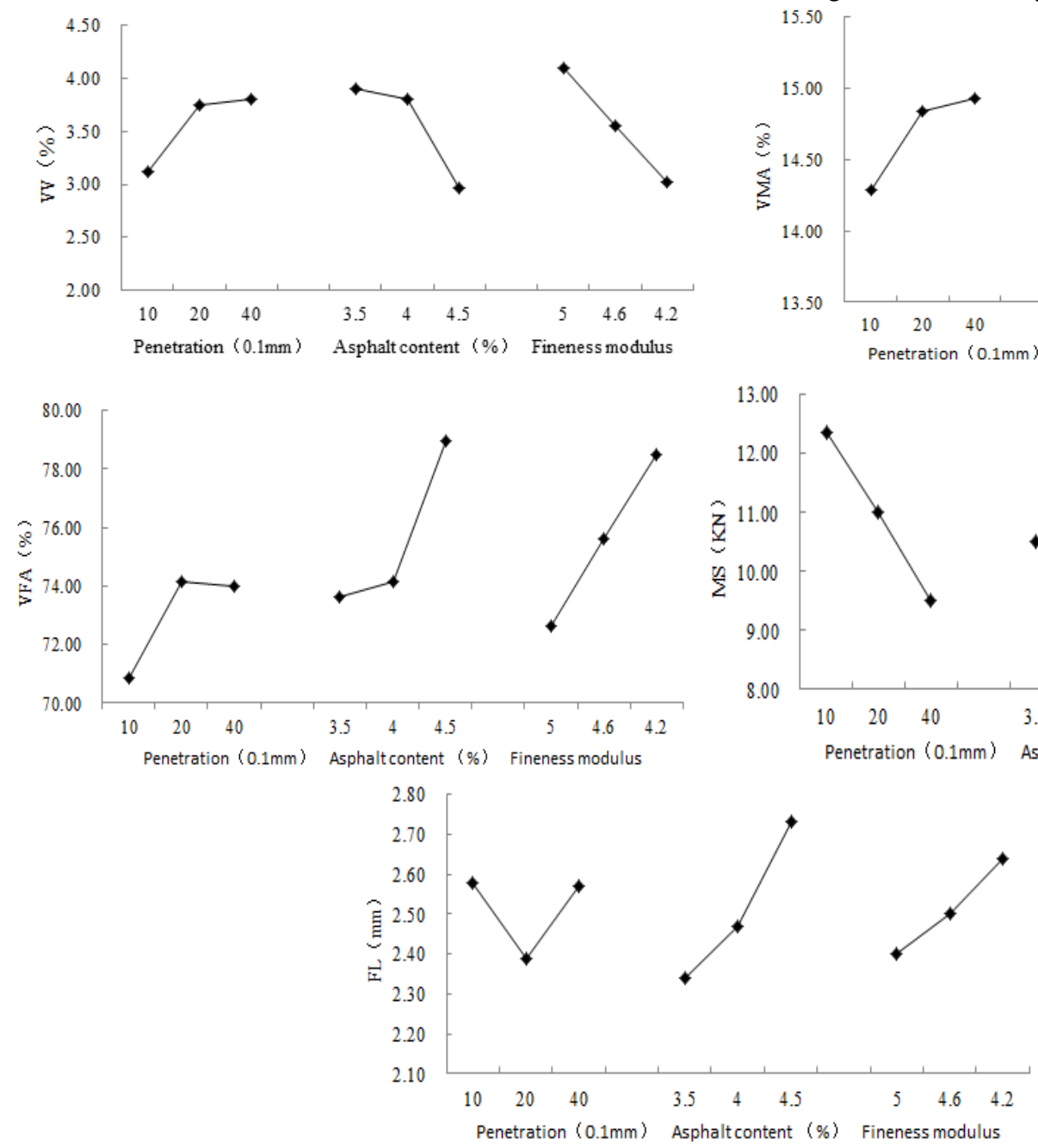

FIGURE I.

CURVE OF INDEX CHANGING WITH FACTOR LEVEL

It could be seen from Figure1:

(1)VV and VMA increased as the penetration of RAP material increasing, VMA and MS decreased as the penetration material increasing, FL showed out parabolic curve as the penetration changing. The FL get the minimum when the penetration was $20(0.1 \mathrm{~mm})$.

(2)VV and VMA decreased as asphalt content of RAP material increasing, VMA, MS, and FL increased as the asphalt content increasing.

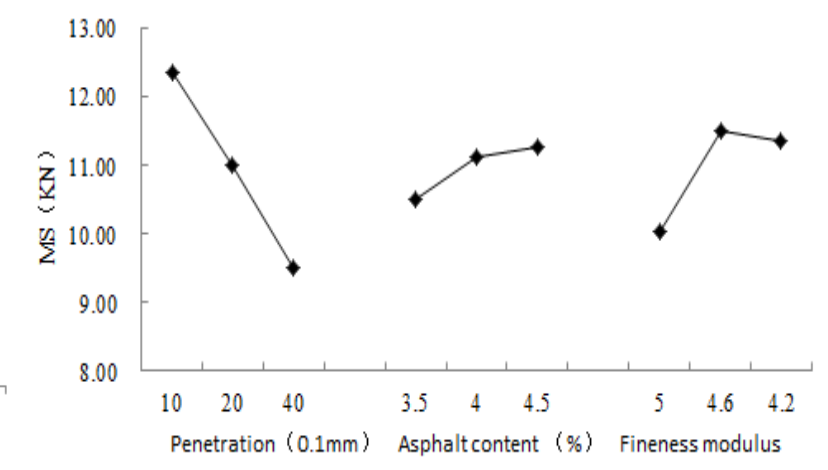

parameters, fineness modulus of RAP had a most siginaficant impact on the mix proportion design volume parameters, and then followed by asphalt content and penetration. The reason was that, calculation of the volume parameters was completed by asphalt content and penetration. As for the mechanical properties and durability, they had a closer relationship withthe aging degree, so the most important influencing factor to stabilityof mixture was aging degree of old asphalt.

The curve that index changed with the factor levels according to intuitive analysis results was showed in Figure1.

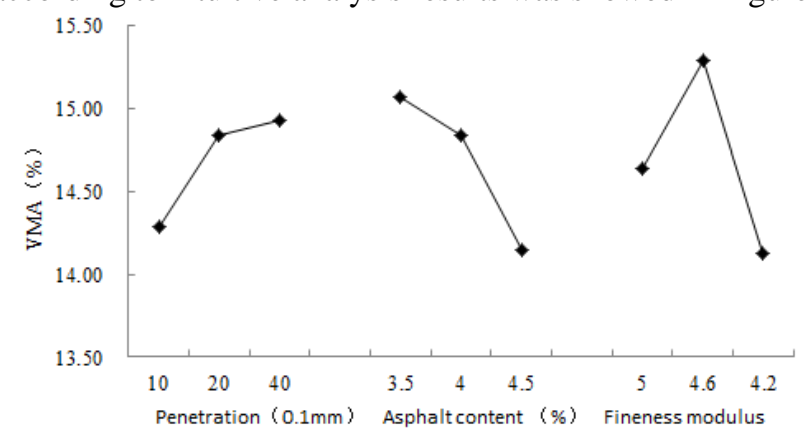


marshall specimens and then conduct rutting test and immersion Marshall test, the results showed in TABLE4.

TABLE IV. PAVEMENT PERFORMANCE OF REGENERATION MIXTURE

\begin{tabular}{|c|c|c|}
\hline $\begin{array}{c}\text { Serial } \\
\text { number }\end{array}$ & DS (T/mm) & MS $_{\mathbf{0}}(\mathbf{\%})$ \\
\hline 1 & 2025 & 83.79 \\
\hline 2 & 2207 & 85.63 \\
\hline
\end{tabular}

\begin{tabular}{|l|l|l|}
\hline 3 & 2370 & 90.09 \\
\hline 4 & 1893 & 88.24 \\
\hline 5 & 1942 & 90.25 \\
\hline 6 & 1820 & 93.05 \\
\hline 7 & 1906 & 92.67 \\
\hline 8 & 1411 & 91.91 \\
\hline 9 & 1505 & 94.12 \\
\hline
\end{tabular}

The intuitive analysis according to test result were showed in TABLE5.

TABLE V.

PAVEMENT PERFORMANCE INTUITIVE ANALYSIS RESULTS

\begin{tabular}{|c|c|c|c|c|c|c|c|}
\hline \multicolumn{5}{|c|}{ DS (T/mm) } & \multicolumn{5}{c|}{ MS $_{\mathbf{0}}(\mathbf{\%})$} \\
\hline $\mathrm{T}_{1}$ & 6602 & 5824 & 5256 & $\mathrm{~T}_{1}$ & 259.51 & 264.7 & 268.75 \\
\hline $\mathrm{T}_{2}$ & 5655 & 5560 & 5605 & $\mathrm{~T}_{2}$ & 271.54 & 267.8 & 267.99 \\
\hline $\mathrm{T}_{3}$ & 4822 & 5695 & 6218 & $\mathrm{~T}_{3}$ & 278.7 & 277.3 & 273.01 \\
\hline $\mathrm{t}_{1}$ & 2200.7 & 1941.3 & 1752 & $\mathrm{t}_{1}$ & 86.5 & 88.2 & 89.6 \\
\hline $\mathrm{t}_{2}$ & 1885 & 1853.3 & 1868.3 & $\mathrm{t}_{2}$ & 90.5 & 89.3 & 89.3 \\
\hline $\mathrm{t}_{3}$ & 1607.3 & 1898.3 & 2072.7 & $\mathrm{t}_{3}$ & 92.9 & 92.4 & 91.0 \\
\hline range & 593.4 & 88 & 320.7 & range & 6.4 & 4.2 & 1.7 \\
\hline $\begin{array}{c}\text { primary and } \\
\text { secondary factor }\end{array}$ & \multicolumn{3}{|c|}{$\mathrm{A} \geq \mathrm{C} \geq \mathrm{B}$} & $\begin{array}{c}\text { primary and } \\
\text { secondary factor }\end{array}$ & \multicolumn{3}{c|}{$\mathrm{A} \geq \mathrm{B} \geq \mathrm{C}$} \\
\hline
\end{tabular}

It could be seen from intuitive analysis results: the order of influence degree that RAP performance had on DS showed bellow: penetration $\geq$ fineness modulus $\geq$ asphalt content; As for the $\mathrm{MS}_{0}$, the result showed bellow: penetration $\geq$ asphalt content $\geq$ fineness modulus.

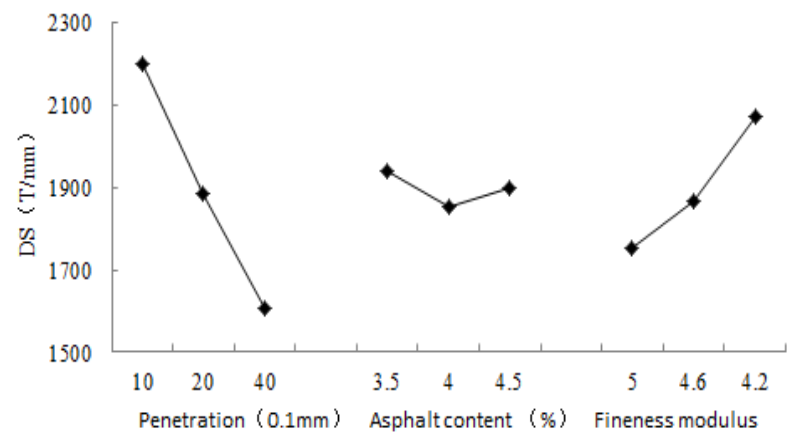

To clearly analyze the influence law of pavement performance under different influencing factors and levels, the curve that pavement performance changed with the factor levels according to intuitive analysis results was showed in Figure2.

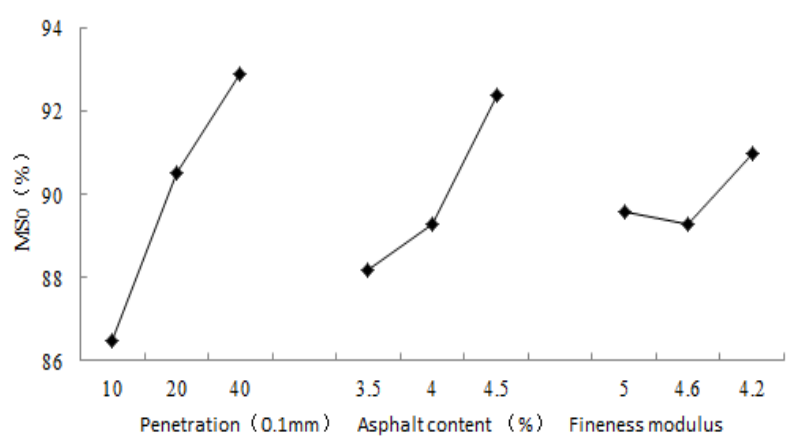

FIGURE II.

CURVE OF PAVEMENT PERFORMANCE CHANGING WITH FACTOR LEVEL

It could be seen from Figure2 that: (1)DS decreased as the penetration of RAP increased, the reason was that, the property of aged asphalt changed, asphalt became hard and brittle, the viscosity became bigger as penetration decreasing. As penetration decreasing, the increase of DS indicated that the temperature performance of aged asphalt was improved. $\mathrm{MS}_{0}$ increased as the penetration increasing, that indicated when the aging degree of asphalt was lighter, the bonding properties with aggregate was better, and then the resistance to water damage capability was improved. (2) $\mathrm{MS}_{0}$ increased as the asphalt content of RAP increasing, but when asphalt content was changing, it had little influence on DS. (3)DS decreasd as fineness modulus of RAP increasing, the aggregate contained little fine aggregate when the fineness modulus became greater, and then inner frictional resistance became little, that led to the strength reduction of mixture. At the same time. Three sets of $\mathrm{MS}_{0}$ data were stable, it indicated that fineness modulus had little influence on water stability.

\section{CONCLUSION}

(1)Fineness modulus of RAP material had the most siginaficant influence on volumn design parameters of hot mix plant recycling mixture, and then followed by asphalt content and aging degree; As for the mechanical properties, aging degree of RAP material had the most siginaficant influence, mechanical properties increased as aging degree decreasing.

(2)The high-temperature performance of recycled materials was improved by a certain extent when aging degree of RAP asphalt was at a higher level, at this time 
there was a clear decline to the property of resistance towards water damage.

(3)The high-temperature performance of hot mix plant recycling mixture decreased as the fineness modulus increasing, the inner frictional resistance became little when the fineness modulus became greater, that led to the strength reduction of mixture.

\section{REFERENCES}

[1] Zhi-ping HU, Xing-dong LIU, Yi XIANG. Application of hot mix plant regenerationin large and medium road repair project[J].Journal of Highway and Transportation Research and Development, 2014,(4):7-9

[2] Ling YU, Jia-dong DIAO, Yan-hai YANG.Evaluation and research on performance of hot mix asphalt plant regeneration technology[J]. Journal of China \& Foreign Highway, 2014,34(2):263-267

[3] Gui-jin WU. Probe on Marshall Mix Design Method of Hot Mix Asphalt Plant Regeneration Mixture[J].Highway, 2011,(5):185-188

[4] Ge-sen WU, Yu-hong LI, Li-xin SITU. Study on Mix Design of Hot Mix Asphalt Plant Regeneration Mixture with High Fly[J], Highway, 2014,(10):251-254.

[5] Yang FANG, Yu LIU, Guo-min ZHANG. Study onhigh-temperature performance of Hot Mix Asphalt Plant Regeneration Mixture with High Fly[J], Highway, 2013,(4):99-103.

[6] Yang FANG, Shan-qiang LI, Yu LIU.WaterStabilityof Central Plant HotRecyclingMixtures[J].Journal of Chongqing Jiaotong University(Natural Science), 2013,32(5):961-964. 